\title{
Programa de Educação pelo Trabalho em Saúde: experiência da Educação Interprofissional na graduação
}

\author{
Education Program through Work in Health: experience of Interprofesional Education at the level
} of degree

Programa Educación a través del Trabajo en Salud: experiencia de Educación Interprofesional a nivel de pregrado

\section{Resumo}

Diante da complexidade que o campo da saúde apresenta e das dificuldades de sistemas de saúde no mundo todo, a Educação Interprofissional (EIP) ganhou maior destaque enquanto estratégia na formação de profissionais do setor. A partir da experiência do Programa de Educação pelo Trabalho em Saúde/Interprofissionalidade (PET-Saúde/EIP), realizado por uma Universidade pública do sudeste do país, em parceria com uma Secretária Municipal de Saúde, essa pesquisa analisou diários de campo de sete estudantes a partir da Análise de Conteúdo, com pré-análise, exploração do material e tratamento dos resultados. Buscou-se analisar a vivência da EIP em saúde a partir das experiências dos estudantes dos grupos, (PET-Saúde/EIP) em seu primeiro ano de funcionamento. Os resultados indicaram cinco categorias: "Concepções sobre Interprofissionalidade", "Competências Colaborativas", "Práticas Colaborativas", "Dificuldades vivenciadas no PET-Saúde/Interprofissionalidade" e "Potencialidades da Educação Interprofissional". Apesar dos desafios, a experiência mostrou grande potencial no desenvolvimento de práticas colaborativas e interprofissionais

Palavras-chave: Educação interprofissional; Práticas colaborativas; Interprofissionalidade; PET-Saúde; Atenção básica.

\begin{abstract}
Given the complexity that the health field presents and the difficulties of health systems worldwide, Interprofessional Education (EIP) gained greater prominence as a strategy in the training of professionals in the sector. Based on the experience of the Education Program for Work in Health / Interprofessionalism (PET-Saúde/EIP), carried out by a public university in the southeast of the country, in partnership with a Municipal Health Department, this research analyzed field data from seven students. from Content Analysis, with pre-analysis, material exploration and treatment of results. We sought to analyze an experience of EIP in health from the experiences of students in the groups (PETSaúde /EIP) in its first year of operation. The results indicated five categories: "Concepts on Interprofessionality", "Collaborative Skills", "Collaborative Practices", "Difficulties experienced in PET-Health/Interprofessionality" and "Potentials of Interprofessional Education". Despite the challenges, a known experience has great potential in the development of collaborative and interprofessional practices.
\end{abstract}

Keywords: Interprofessional education; Collaborative practices; Interprofessionality; PET-Health; Primary care.

\section{Resumen}

Dada la complejidad que presenta el campo de la salud y las dificultades de los sistemas de salud a nivel mundial, la Educación Interprofesional (EIP) cobró mayor protagonismo como estrategia en la formación de profesionales del sector. A partir de la experiencia del Programa de Educación para el Trabajo en Salud / Interprofesionalismo (PETSaúde/EIP), realizado por una universidad pública del sureste del país, en alianza con un Departamento Municipal de 
Salud, esta investigación analizó datos de campo de siete estudiantes. de Análisis de Contenidos, con pre-análisis, exploración de materiales y tratamiento de resultados. Se buscó analizar una experiencia de EIP en salud a partir de las experiencias de los estudiantes en los grupos (PET-Saúde / EIP) en su primer año de funcionamiento. Los resultados indicaron cinco categorías: "Conceptos sobre interprofesionalidad", "Habilidades colaborativas", "Prácticas colaborativas", "Dificultades experimentadas en PET-Salud/Interprofesionalidad" y "Potencialidades de la educación interprofesional". A pesar de los desafíos, una experiencia conocida tiene un gran potencial en el desarrollo de prácticas colaborativas e interprofesionales.

Palabras clave: Educación interprofesional; Prácticas colaborativas; Interprofesionalidad; PET-Salud; Atención primaria.

\section{Introdução}

A Organização Mundial de Saúde (OMS) tem indicado a Educação Interprofissional (EIP) como uma importante estratégia de potencialização do trabalho em saúde. Trata-se de uma proposta em que "duas ou mais profissões aprendem sobre os outros, com os outros e entre si para a efetiva colaboração e melhora dos resultados na saúde" (OMS, 2010 p.13). A EIP visa assim, fortalecer sistemas de saúde e melhorar a qualidade do trabalho em equipe entre os diferentes profissionais da saúde em um novo nível de interação entre eles.

Neste contexto, as práticas colaborativas se destacam como um conteúdo importante da EIP, nisso que profissionais de saúde de diferentes áreas têm como proposta a oferta de um cuidado integral em saúde, envolvendo os usuários e suas famílias, cuidadores e comunidades, para atenção à saúde da mais alta qualidade em todos os níveis da rede de atenção (OMS, 2010).

Acredita-se que a formação sustentada pelas discussões trazidas pela EIP (comunicação interprofissional, atenção centrada no usuário, família e comunidade, funcionamento integrado das equipes, resolução de conflitos, clareza de papéis e liderança colaborativa) tem potencialidade de transformação daquele paradigma hegemônico, baseado em relações hierárquicas e em uma lógica curativista e médico centrado.

A “comunicação interprofissional” se refere a um processo de negociação continuo, por meio de discussões respeitosas, incluindo usuários/famílias/profissionais/ gestores. Tal competência se articula a proposta de uma "atenção centrada no usuário", família e comunidade, na medida em que os profissionais e estudantes devem integrar, valorizar e envolveresses atores sociais na concepção e implementação do cuidados em saude. A “dinâmica de funcionamento de equipe”, por sua vez, relaciona-se com a capacidade de reflexão sobre trabalhar em conjunto de maneira eficaz. Requer práticas de cooperação, comunicação aberta, escuta atenta, resolução de conflitos e tomada de decisão, sem perder de vista o caráter colaborativo, respeitando a centralidade da pessoa/família na elaboração e execução de ações. Nesta discussão, entende-se que o conflito é inerente às relações e pode ser causado por diferenças de perspectivas e abordagens, por exemplo. Mas também pela ausência de comunicação, clareza de papéis, sobrecarga, dentre outros. Dessa forma, a "resolução de conflitos interprofissionais" é um domínio que precisa ser trabalhado para que se compreenda suas possíveis causas e se construa estratégias coletivas de resolução, de modo que os interesses do sujeito/ família/ comunidade permaneçam central na direção do trabalho em equipe. A “clareza de papéis", como mais uma competência trabalhada pela EIP, consiste no entendimento dos profissionais sobre suas próprias funções e as dos colegas de outras áreas, com vistas a alcançar os objetivos anunciados pelo sistema de saúde. Por fim, a "liderança colaborativa" é trabalhada principalmente em dois aspectos: na orientação de tarefas, auxiliando a alcançar objetivos; e na orientação de relacionamentos, ajudando os membros a trabalharem em conjunto (CHIC, 2010).

Assim, a EIP se afirma como uma estratégia que, por meio do ensino, têm a intenção de fomentar práticas colaborativas e reparar práticas isoladas de trabalho no cuidado à saúde. No Brasil, o debate sobre EIP tem como pano de fundo o Sistema Único de Saúde (SUS), que traz na sua interface com a educação, a Política de Educação Permanente em Saúde, por exemplo, a qual destaca a imprescindibilidade, para a consolidação desse sistema, de práticas de trabalho em equipe cada vez mais colaborativas e centradas no usuário (Peduzzi, 2016). 
Associa-se a essa discussão, também, o Programa de Educação pelo Trabalho em Saúde (PET-Saúde), o qual comparece como mais um dos componentes das políticas de Educação ligadas a Saúde, com o objetivo de fomentar processos formativos na direção da integração entre as diversas profissões da saúde com vista a integralidade do cuidado (Fonsêca \& Junqueira, 2017). A última edição desse Programa destacou a interprofissionaliade, como temática orientadora das suas práticas, sendo denominado: PET-Saúde/EIP.

Diante dessa discussão, é possível questionar: como a EIP tem se materializado no cotidiano das práticas? Quais as experiências de estudantes da graduação que vivenciam essa formação interprofissional por meio do PET-Saúde?

A partir dessas questões, esse estudo objetivou analisar a vivência Interprofissional em saúde a partir das experiências dos estudantes no PET-Saúde/EIP, em seu primeiro ano de funcionamento. Com isso busca-se contribuir para o debate acerca da EIP no espaço da universidade, entendendo que a formação dos estudantes no debate da saúde pública necessita de mudança de paradigmas, de processos de trabalho educacionais e das práticas, tanto discente quanto docente, no caminho de uma transversalização das relações para um trabalho integrado.

\section{Metodologia}

Diante da objetivo do estudo, o método qualitativo mostrou-se o mais adequado, visto que sua finalidade é a compreensão dos sentidos, das intencionalidades e das questões subjetivas inerentes aos atos, às atitudes, às relações e às estruturas sociais (Minayo, 2008).

A pesquisa foi realizada no contexto do PET-Saúde/EIP, em uma universidade em parceria com a prefeitura do município em questão. Sua proposta foi promover a interação entre estudantes da saúde de diferentes cursos e assim, exercitar e efetivar a interprofissionalidade já na formação dos estudantes. Os eixos principais do projeto foram a EIP e o matriciamento, para o planejamento e realização das ações na Atenção Básica (AB).

Para esse PET-Saúde/EIP foram selecionados cinco Unidades de Saúde (US) do município e nove cursos diferentes (Enfermagem, Farmácia, Fisioterapia, Fonoaudiologia, Medicina, Nutrição, Odontologia, Psicologia, e Terapia Ocupacional), com equipes formadas por cinco estudantes bolsistas e dois voluntários, divididos de forma aleatória, visando variedade entre os discentes atuando em conjunto. Os tutores e coordenadores (professores da universidade) e os preceptores (profissionais de saúde do serviço) também foram de profissões diferentes, de modo que não havia um tutor nem um preceptor específico para cada aluno. Logo, o contato entre estudantes, tutores e preceptores se pretendeu interprofissional, interdisciplinar, autônomo e flexível, na medida em que cada equipe, de cada US, se formava diferenciada, com o objetivo de iniciar o processo de integração entre as diversas formações.

Diante do objetivo dessa pesquisa e do contexto apresentado, foram convidados a participarem desse estudo os discentes de todas as cinco US contempladas pelo PET-Saúde/EIP. Destes, sete estudantes de diferentes formações (Farmácia, Fonoaudiologia, Medicina, Nutrição, Psicologia e Terapia Ocupacional), se disponibilizaram a contribuir com essa pesquisa por meio de seus diários de campo, produzidos ao longo do primeiro ano de participação no PET- Saúde/EIP, compreendido entre abril/2019 a abril/2020. A utilização dos diários e relatos escritos ocorreu após permissão de seus autores sob Termo de Consentimento Livre e Esclarecido. Vale destacar que o projeto foi aprovado pelo comitê de ética (n. 3.810.065) e pela Secretaria Municipal de Saúde de Vitória.

Assim, essa pesquisa se utilizou de sete diários de campo como técnica de produção de dados. Refere-se aos participantes que escreveram esses diários de campo como: E1, E2, E3, E4, E5, E6 e E7. A escrita do cotidiano, práticas e experiências marcantes possibilitam registros, aos quais o ato de escrita e releitura permitem reflexões e análises (Hess \& Weigand, 2006). Enquanto instrumento de pesquisa, os diários de campo são fontes de informações acerca dos processos de 
trabalho e ocorrências que extrapolam textos tradicionais dada a suposta flexibilidade, ao permitir impressões e a colocação do próprio autor no registro dos acontecimentos. É possível acompanhar toda uma experiência de trabalho por meio da leitura e análise de diários de campo (Lourau, 1993).

A partir desses diários, para análise dos dados foi aplicada a técnica de Análise de Conteúdo de Bardin (2009), que consistiu em três etapas: pré-análise, exploração do material, tratamento dos resultados. Na etapa de pré-análise, foram feitas várias leituras dos diários de campo, no sentido de deixar se afetar pelos dados, destacando as impressões iniciais. Nesta etapa, também foram destacados os trechos dos diários de campo que contemplavam o objetivo desta pesquisa. Em seguida, foi realizada a exploração do material, com a categorização dos trechos selecionados, agrupados e classificados por semelhança. Essa etapa resultou em cinco categorias: "concepções sobre interprofissionalidade", "competências colaborativas", "práticas colaborativas", "potencialidades da interprofissionalidade" e "dificuldades vivenciadas no PET-Saúde/Interprofissionalidade". Por fim, a última etapa foi realizada o tratamento dos resultados, que culminou na análise reflexiva dos dados, com o intuito de expressar os sentidos e significados conferidos às mensagens analisadas.

\section{Resultados}

\section{Concepções sobre interprofissionalidade}

Essa categoria apresenta os entendimentos descritos pelos estudantes em seus diários de campo sobre interprofissionadade. Dos sete diários analisados, cinco (E1, E2, E4, E5 e E7) referem explicitamente, sua concepção sobre a temática em questão.

Para o estudante (E1) a interprofissionalidade se refere a "troca de saberes e a mudança nas relações de poder do trabalho na Atenção Básica". Nesta direção, outro estudante (E7) afirma a interprofissionalidade como "trocas"que possibilitam a criação de ações benéficas e significativas para aqueles a quem é voltada. Para outro estudante, trata-se de um "esforço mútuo, do fazer com o outro, afetar e ser afetado" (E4).

Outra estudante refere a Interprofissionalidade como "uma abordagem na qual os membros de mais de uma profissão aprendem juntos, interativamente, com o propósito explícito de melhorar as práticas colaborativas em saúde" (E5).

Por fim, nesta categoria, comparece um entendimento que relaciona a interprofissionalidade à soberania do sujeito, de modo a se afirmar "como quebra de paradigma" (E2).

\section{Competências Colaborativas}

Essa categoria tem por objetivo apresentar as competências colaborativas descritas pelos estudantes nos diários de campo, para a efetivação da interprofissionalidade e práticas colaborativas. Na literatura sobre tal temática são enumeradas as seguintes competências: comunicação interprofissional, atenção centrada na pessoa, liderança colaborativa, resolução de conflitos, clareza de papéis, dinâmica no trabalho em equipe (CHIC, 2010).

Vale destacar que algumas dessas competências não foram nomeadas como tais nos diários de campo pelos estudantes, apesar de trazerem os sentidos dessas competências. Infere-se que isso pode se relacionar ao fato de naquele tempo e espaço, os estudantes ainda não terem passado pela momento de aprofundamento teórico sobre essas temáticas, ocorrido no segundo ano de execução do PET-Saúde/EIP. No que se refere a "dinâmica no trabalho em equipe", ela sempre compareceu associada às práticas colaborativas registradas nos diários ou às dificuldades relatadas, por isso não foi explicitamente categorizada neste tópico.

Das competências citadas, a "comunicação interprofissional" compareceu em seis diários de campo (E2, E4, E5, E6 e E7), se referindo ao processo de escuta e comunicação com os usuários e entre os profissionais da equipe. A estudante E2 destaca 
que a comunicação entre os profissionais "possibilita o avanço nas atividades"; acrescido disso, relata a experiência de criação de um grupo de WhatsApp com os usuários como uma ferramenta importante de comunicação, que contribuiu no aumento da presença dos usuários no grupo proposto pelo PET-Saúde/EIP. Para a estudante E6, "conversar, ouvir, entender a realidade do usuário"(...) compreender "como o individuo lida com a doença" (...) ajuda muito para elaboração de estratégias de comunicação" com o usuário e entre os profissionais.

A "atenção centrada na pessoa", por sua vez, compareceu em quatro diários de campo (E2, E3, E4 e E5). Essa competência se efetivou em momentos de planejamentos de ações, planejamentos de rodas de conversa, atendimentos propriamente ao usuário e como princípio dos serviços, vivenciado quando o estudante participou de uma reunião de rede, que integrou "diferentes áreas do poder público"(E2) centradas no cuidado à população. O estudante E3 descreve a construção de um “cardápio alimentar”, junto à usuária, "levando em consideração o contexto sociocultural em que ela está inserida, [pensando] em opções acessíveis, nutritivas e de fácil execução" (E3).

Ainda referente à competência "atenção centrada na pessoa", outra estudante (E4) descreve a indicação a uma usuária de participação no "projeto Hiperdia". Nas palavras da estudante:

Incialmente, com o intuito de que ela possa se aproximar de outras pessoas que vivem sob uma condição de saúde semelhante a dela, mas que, talvez. lidam de uma outra forma. Possibilitar a criação de vínculos e talvez chegar a uma outra compreensão de autocuidado, que não imposta pelos profissionais, mas construída ali naquele espaço, a partir das trocas, dos vínculos e do poder transformador que espaços como esse, que planejamos, produzem (E4).

A competência "resolução de conflitos"compareceu em um único diário de campo, que aconteceu em reunião de equipe PET-Saúde/EIP. Nas palavras da estudante:“pudemos expor e avaliar alguns descontentamentos com relação ao acúmulo de atividades, falhas de comunicação e de envolvimento acerca do grupo [que desenvolvíamos]. A partir disso, direcionamos algumas responsabilidades e acordamos movimentos futuros" (E2)

Compareceu ainda, em um único diário de campo, a competência“clareza de papéis”, que para a estudante (E4) referese a percepção do seu papel profissional como algo importante para entender sua função na equipe e nas trocas com as colegas. A mesma estudante também descreveu a competência "liderança colaborativa" ao relatar uma divisão de tarefas baseada na participação colaborativa do planejamento, compartilhamento de tarefas, e cuidado em inserir os usuários no desenvolvimento de cronograma para um grupo que estava sendo formado.

\section{Práticas Colaborativas}

Esta categoria refere-se às experiências coletivas entre estudantes, ou estudantes e profissionais com diferentes experiências, trabalhando em conjunto na execução ou planejamento de alguma ação.

Neste sentido comparecem: reuniões envolvendo estudantes, Agentes Comunitários de Saúde (ACS) e enfermeira para planejar atividades a serem realizadas em visita domiciliar a uma idosa (E1); reunião para "organização de um fluxograma para atendimentos de pacientes no campo da saúde mental" (E1); criação conjunta de "material que (...) orientam sobre a resolução de conflitos em lares" (E1); visita domiciliar com orientações sobre alimentação saudável, melhor uso e armazenamento de medicação e incentivo ao exercício físico (E1 e E5); planejamento, escrita de projeto de grupo de saúde e execução do grupo (E2, E4, E5, E6 e E7); “elaboração do projeto de pesquisa sobre a saúde do idoso” (E3); "reunião e elaboração de oficinas com a pedagoga" como atividade do Programa Saúde na Escola (PSE), voltadas a estudantes do $8^{\circ}$ e $9^{\circ}$ ano (E3), participação em ação do PSE junto a vários profissionais de saúde (E5); preparação da semana de aleitamento materno (...) incluindo uma roda 
de conversa com a presença de uma fonoaudióloga" (E5); ação em um Centro Municipal de Educação Infantil (CMEI), com confecção de música sobre combate aos piolhos (E5) e "confecção de horta terapêutica" (E6).

Em relação a essas práticas colaborativas, a estudante relata ser "prazeroso perceber que todas as estudantes tentam contribuir de alguma forma, o que reforça que o projeto é, de fato, coletivo" (E2). Ainda sobre esses processos de trabalho colaborativo, outro estudante evidencia ser "mais perceptível a existência de uma coesão grupal e de um objetivo compartilhado nessa ação [construída pelos estudantes do PET- Saúde/EIP]. Acredito que todas nós estamos entendendo do que se trata a ação, quem é o nosso público e como dialogar com ele" (E4).

Das práticas colaborativas que usou o contexto territorial, destaca-se um diário de campo (E3): o qual relata que a partir de visitas ao território foi possível "discutir algumas propostas que tem surgido durante a vivência dentro da comunidade, assim, pensamos em desenvolver atividades que sejam estabelecidas como critérios terapêuticos no Projeto Terapêutico Singular" (E3).

\section{Potencialidades da Interprofissionalidade}

Essa categoria apresenta as potencialidades de participação no PET-Saúde/EIP, descritas pelos participantes em seus diários de campo. Todos os sete diários de campo analisados descrevem potencialidades de tal participação. São muitas as potencialidades trazidas pelos estudantes, umas focadas em questão mais acadêmicas, como o "desenvolvimento técnico e científico" (E1), outras relativas a atuação propriamente dita, no espaço do serviço, como, a "integração entre as diferentes áreas do poder público que atende a população" (E2).

Dos sete diários analisados, cinco (E2, E3, E4, E5 e E7) apresentam como potencialidade a troca de saberes e práticas entre as diversas formações participantes do PET-Saúde/EIP e não participantes, como aqueles profissionais da AB que não estão como preceptores. Para uma estudante, é esse compartilhamento que possibilita "pensar em estratégias mais eficazes para alcançar o público da US, mesmo em atividade educativas" (E2). Outra estudante destaca a possibilidade, a partir dessa integração, de expansão da atuação, "de maneira a favorecer a atenção ao cidadão" (E1).

Ressalta-se ainda, a potencialidade de troca também com o usuário, que se relaciona, segundo E2, a construção de um interesse pelo saber do outro. Nas palavras da estudante: "é bonito ver como as ideias surgem e se potencializam quando pessoas diferentes se juntam (...) conversar com o preceptor acerca de algumas relações entre saúde mental e bucal, [em] situações que eu nem fazia esse vínculo" (E2).

Dessa forma, fala-se também, da potencialidade de apreender a valorizar o trabalho e respeitar o conhecimento técnicocientífico de cada profissão da área da saúde, trabalhar em equipe (E3), que, por sua vez, segundo a estudante, repercutirá no fortalecimento de vínculo entre as profissões. Neste sentido, outra estudante (E7) apresenta a potencialidade de "estar junto e conhecer o trabalho de outras áreas (...) e assim, observar o que chega de demanda de atendimento pelos usuários".

Os estudantes (E2, E3, E4, E5 e E7) descrevem ainda, como potencialidade o PET- Saúde/EIP propiciar aquisição de conhecimentos e problematizações a partir da experiência de acompanhamento do cotidiano da AB. Nas palavras da estudante: trata-se de "vivenciar na prática a realidade da saúde local no âmbito do Sistema Único de Saúde". Duas estudantes (E2 e E5) destacam que nesta vivência foi possível conhecer "algumas diferenças entre as medicações" e "o sistema de dispensa de medicamentos", entendida como uma potencialidade, já que as estudantes não são do curso de farmácia. Outra estudante, por sua vez, escreve sobre as reflexões disparadas a partir desse contato com a farmácia, no que se refere ao "processo de medicalização da vida, onde para tudo existe um diagnóstico, um medicamento e um único caminho a ser seguido, o modelo da 'clínica tradicional', que passa bem longe da 'clínica ampliada"” (E4). Nesta reflexão a estudante explica que entende que não se trata de "abolir os medicamentos", mas agregar "outras formas de intervir e cuidar" (E4). 
A estudante E5 destaca nesta discussão a potencialidade deste programa possibilitar a aquisição de conhecimentos que poderão ser aplicados tanto à sua graduação quanto à sua experiência de interprofissionalidade, como, por exemplo, “contato direto com os pacientes, aferição de pressão, avaliação antropométrica, avaliação do nível glicêmico dos pacientes diabéticos, preenchimento dos dados no prontuário do paciente, técnicas de amamentação” (E5).

Outra estudante afirma como potencialidade o "acesso a trajetória do apoio matricial no município mostrando a importância de se estabelecer diretrizes para orientar a ação profissional e a organização dos serviços frente as fortes demandas e desafios diários que podem se transformar em barreiras para que o matriciamento aconteça e o funcionamento da rede seja de fato consolidado" (E4).

Os estudantes escrevem também, sobre a potencialidade dessa participação no PET-Saúde/EIP provocar mudanças em seus processos de formação enquanto humanos, para além da formação profissional (E3, E4 e E5). A estudante explica: “conheci um território novo e com realidades diferentes da minha, fui confrontada pelos pacientes com perguntas (...) aprendi coisas das quais não sabia que tinha dúvida” (E5). Outra estudante refere que passou a se sentir mais segura, também com o apoio das tutoras, "em relação as possibilidades de cuidado, saber escutar e fazer com o outro" (E4).

Nesta mesma direção, outra estudante escreve sobre a potencialidade de construção de um olhar para “os sujeitos, como muito mais que o impedimento que possui”, o que significa, segundo a estudante, atentar-se ao contexto e as relações que constituem esse sujeito. Para ela, isso "favorece uma adesão maior das famílias e indivíduo, por tratar-se de ações viáveis para seu contexto, considerando a sua realidade, já que sua saúde vai além de aspectos biológicos e fisiológicos” (E7).

São trazidos ainda como potencialidade a possibilidade de participação pelos estudantes em reuniões de equipe para conhecimento dos casos atendidos na Unidade de Saúde (E2), participação em reunião de colegiado gestor (E5), visita domiciliar (E5), realização de ações, contextualizadas com outras atividades (E1), criação com outras monitoras de grupo de saúde (E2 e E6), poder avaliar o trabalho e "expor opiniões"(E1), atuar na "resolução de conflitos no trabalho" (E1). Assim, o PET-EIP possibilita "vivenciar o que se aprende na faculdade na prática" (E6).

Neste sentido, a estudante escreve: "estamos conseguindo articular o conteúdo dos textos lidos (principalmente os textos sobre EIP e trabalho em equipe) com a nossas vivências na US e na universidade de forma muito construtiva, uma vez que estamos conseguindo nos expressar melhor, mostrar nossos pontos de vista e chegar a um certo consenso de tudo o que foi discutido" (E4).

\section{Dificuldades vivenciadas no PET-Saúde/Interprofissionalidade}

Esta categoria apresenta as dificuldades relatadas pelos estudantes ao longo da sua participação no primeiro ano do PET-Saúde/EIP. Dos sete diários, apenas um (E5) não relatou nenhum tipo de dificuldade. Dentre as dificuldades descritas comparecem aquelas referentes a questões de entendimentos, bem como desafios relacionais e organizacionais.

Os desafios organizacionais se relacionaram principalmente, à dificuldade de "encontrar horários em comum" entre os integrantes do PET-EIP. Diante desse desafio, E2 e E3 destacaram consequências para a efetivação da Interprofissionalidade, já que "fica difícil alinhar as produções e decisões coletivas (...) o planejamento do grupo" (E2).

Os estudantes (E1, E2 e E6) apontaram ainda, em seus diários de campo, como desafio as "trocas de saberes" (E1), a"discussão coletiva" (E2), bem como, “a mudança nas relações de poder do trabalho na Atenção Básica” (E1). Neste sentido, E6 destaca a dificuldade de "sair da inércia, cada um tem seu entendimento dos passos para começar a elaborar um material, um tem a iniciativa, outro a criatividade, outro a organização".

Ainda sobre as dificuldades de trocas entre os integrantes do PET-Saúde/EIP, E3 destaca a “falta de adesão dos próprios participantes das equipes de referências em relação aos casos que exigem um nível de complexidade maior” (E3). E6 também 
aborda sobre os erros de divisão de tarefas (envolvendo estudantes e servidores da unidade) ao planejarem e organizarem ações para um grupo de saúde.

Compareceram ainda como desafio no trabalho dos estudantes no PET-Saúde/EIP, as falhas de comunicação entre estudantes e usuários e entre estudantes e profissionais (E2 e E4). Próxima a essa discussão, E7 descreve como dificuldade o fato dos estudantes do PET-EIP serem pouco conhecidos na US e, por vezes, confundidos com residentes e estagiários presentes nesse serviço de saúde.

Compareceram nos diários de campo (E3 e E4) ainda, como desafio a essa prática, a insegurança por parte dos estudantes. Essa insegurança comparece de diferentes modo, para E3, a insegurança dele e dos colegas se relaciona “ao que fazer [em relação ao trabalho], o que vamos pesquisar”;já E4 relaciona a insegurança à primeira experiência prática ao longo da graduação. Acrescido disso, o estudante descreve dificuldade em relacionar teoria e prática:“A insegurança é muito forte quando não consigo colocar em prática aquilo que eu acredito, aprendo nas aulas, leio nos textos, enfim” (E4). A estudante também escreveu como desafio a "responsabilidade de fazer diferença na vida do outro"

Outra dificuldade descrita (E3 e E4), inclusive como um obstáculo à interprofissionalidade, se refere a um ensino fragmentado no espaço da universidade, "sem articulação entre os cursos, principalmente no campo da saúde" (E4). Nesta direção, E3 aponta como desafio o fato da interprofissionalidade não estar contemplada nos currículos dos cursos de graduação.

Nesta direção, os estudantes (E1 e E2) apresentam como dificuldade a pouca compreensão do que é interprofissionalidade por parte de profissionais, docentes e estudantes. Para E1 era difícil entender os objetivos de certas ações debatidas em reuniões de equipe, descritas como interprofissionais. E2 relata a atividade de confecção de "cartazes do próprio núcleo de saber, não havendo troca ou discussão coletiva para a produção dos mesmos”, aparentemente, como pouco condizente à proposta interprofissional, apesar de ter sido indicada como tal.

\section{Discussão}

Os resultados dessa pesquisa apontam a proximidade das concepções trazidas pelos estudantes aos entendimentos teóricos relacionados à EIP, que pode significar uma repercussão da vivência no PET-Saúde/EIP, mas também a própria experimentação do SUS. Problematiza-se neste estudo a paridade dos conceitos que circundam a interprofissionalidade e as concepções já consolidadas neste sistema de saúde brasileiro, como, a cogestão, a participação social, a integralidade. Destacase ainda, as similaridades entre as potencialidades apontadas pelos estudantes, relacionadas à participação no PET-Saúde/EIP e as dificuldades vividas ao longo do primeiro ano neste programa.

As concepções dos estudantes sobre a interprofissionalidade se referem à troca, a mudanças nas relações de poder e a um aprendizado com o outro, inclusive apontadas também, como potencialidade da interprofissionalidade. São entendimentos que se articulam às competências interprofissionais, enfatizando a centralidade dos sujeitos, que, por sua vez, se conecta ao paradigma emergente de valorização das subjetividades no construção de um cuidado singular em saúde (Belotti, 2019).

Assim, a interprofissionalidade dialoga com o paradigma emergente e pode ser entendida como o trabalho colaborativo realizado por profissionais de saberes diferentes, sustentado na transversalização das relações, em que os sujeitos, a família e a comunidade são centrais no cuidado. Sua principal finalidade é, por meio dessa atuação integrada, promover saúde para o outro/usuário e para si/profissionais (Peduzzi, Oliveira, Silva, Agreli \& Neto, 2016; OMS, 2010; CHIC, 2010).

Importante ressaltar esse entendimento trazido também pelos estudantes, de que não se trata unicamente de uma troca que beneficia ao usuário, na medida em que tem a potencialidade de fomentar a integralidade do cuidado; mas também privilegia os profissionais envolvidos, que afetam e são afetados por esse outro (usuário, profissional e gestor). Entende-se esse "afetar e ser afetado" articulado à potencialidade da participação no PET-Saúde/EIP, descrita pelos estudantes desse estudo, no que se 
refere à formação humana a partir do contato com diferentes realidades. Isso remete a possibilidade de produção de sujeitos mais ativos, críticos, envolvidos e solidários para a efetivação daquelas ações intersetoriais (vivenciadas pelos estudantes dessa pesquisa) requeridas por um conceito ampliado de saúde (Brasil, 2006). Assim, se afirma a saúde do trabalhador diretamente ligada à saúde que se constrói com o usuário. Em outras palavras, a possibilidade de produção coletiva de um cuidado interfere positivamente também, na saúde deste profissional no que se refere ao trabalho.

Pesquisas (Peduzzi, 2016; Peduzzi, 2017; Lima, Ribeiro, Padilha \& Mourthé Júnior, 2018) apontam que apesar dos desafios de efetivação da interprofissionalidade, quando consolidada diminui o sentimento de solidão dos trabalhadores, na medida em que integram conhecimentos e ação em um processo inventivo de produção de vida para os envolvidos. Para o Ministério da Saúde (Brasil, 2006), tal potencialidade se efetiva pelo fato dessa integração proporcionar a cada trabalhador a ampliação de sua capacidade de analisar e de transformar seu modo de operar a partir do contato com os saberes dos diversos atores sociais com os quais interage. Trata-se possivelmente de uma construção solidária que resulta naquele sentimento de maior segurança para o trabalho, descrito pelos estudantes dessa pesquisa.

No primeiro ano de funcionamento do PET-Saúde/EIP, os estudantes ainda não tinham passado pelo momento de aprofundamento teórico sobre as competências interprofissionais, ocorrido no segundo ano de execução do programa. Apesar disso, mesmo antes da fase de imersão nos seis domínios/competências das práticas colaborativas, os estudantes já traziam os sentidos de tais temáticas em seus diários de campo, o que pode-se relacionar também, com a própria vivência na AB. Esse nível de atenção abarca o trabalho em equipe interdisciplinar e territorializado, como descritos pelos estudantes, com espaços de planejamentos, reuniões de trabalho e matriciamento, sustentado pelos princípios: da universalidade, da acessibilidade e da coordenação do cuidado, do vínculo (equipe-usuário) e continuidade, da integralidade, da responsabilização, da humanização, da equidade e da participação social (Brasil, 2011). Dessa forma, esse cenário de atuação afirma sua potencialidade de propiciar o desenvolvimento da colaboração no exercício das atividades pelos estudantes, mesmo que eles não saibam de antemão as concepções teóricas de cada competência (Peduzzi, 2016; Peduzzi, 2017; Lima et al., 2018).

Nos registros analisados, a "comunicação interprofissional" foi a competência que mais compareceu, seguida pela "atenção centrada na pessoa". De acordo com Previato e Baldissera (2018), dentre os seis domínios, a comunicação é a mais crucial, sendo a mais presente entre os outros, uma vez que, realizada de forma aberta, respeitosa e transversalizada, tem potencial de contribuir na resolução de conflitos, na construção de uma liderança colaborativa (cogestão), no entendimento por parte dos profissionais das contribuições de cada membro da equipe para produção de cuidado (clareza de papéis) e na atenção centrada nas pessoas. A comunicação guia o relacionamento entre serviço e comunidade, profissional e pessoa/família, e entre profissionais da mesma equipe ou de setores diferentes, destacando-se, assim, como uma competência essencial para o desenvolvimento de práticas colaborativas (Previato \& Baldissera, 2018; Peduzzi, 2017).

A "comunicação interprofissional" compareceu ainda, nos diários de campo, como mecanismo de circulação de informações, por meio de um grupo de WhatsApp, que possibilitou inclusive, ampliação da participação dos usuários no grupo proposto. Entende-se a importância da informação em saude (Leite, Brito, Silva, Palha, \& Ventura, 2014), inclusive no que se refere às disponibilidades de ofertas existentes no serviço, como apresentado neste estudo; contudo, faz-se imprescindível não perder de vista que a proposta de uma "comunicação interprofissional" avança na direção da construção de práticas colaborativas envolvendo inclusive o usuário. Previato e Baldissera (2018) destacam aspectos antidialógicos da comunicação por meio de aparatos tecnológicos, como aplicativos de celular, que, por vezes, se caracterizam pela passagem unilateral de informações. As autoras advogam pela afirmação de espaços de diálogo, superando a dicotomia entre o aprender e o ensinar, entre emissor e receptor de informações. 
Entende-se que esse domínio, assim como a "atenção centrada na pessoa", se relaciona à participação social, que se destaca como uma diretriz do SUS de relevância social e política, na medida em que garante que a população esteja envolvida no processo de formulação/decisão e controle das políticas públicas de saúde (Rolim, Cruz \& Sampaio, 2013); o que requisita a comunicação aberta a negociação entre prestadores, gestores, trabalhadores e usuários na avaliação e proposição de orientações das políticas públicas de saúde.

Acrescenta-se a essa discussão, o debate de uma participação social para além dos Conselhos e Conferências de Saúde, assegurados em lei e de grande importância para o SUS; uma participação que se dá no cotidiano dos serviços (Quintanilha, Sodré \& Dalbello-Araujo, 2013), a qual envolve escuta entre profissionais e entre profissionais e usuários, possibilitando entender a realidade, como trazido pelos estudantes nos escritos relativos a "comunicação interprofissional" e, consequentemente, construir práticas condizentes com as necessidades do território.

Aparentemente, essa articulação com o território foi possível de ser vivenciada por alguns estudantes do PETSaúde/EIP, na medida em que, de acordo com o relato de um diário de campo analisado, se construiu propostas terapêuticas no contato com a comunidade. Isso pode se relacionar a potencialidade descrita de vivência das realidades e de problematização de uma "clínica tradicional” na direção de afirmar a clínica ampliada, que segundo a estudante, possibilita agregar "outras formas de intervir e cuidar".

A “atenção centrada na pessoa", por sua vez, segundo os estudantes desse estudo, acontece no planejamento de ações, no atendimento ao usuário e em reunião de rede. Vale problematizar neste ponto se essas ações são realizadas unicamente, de modo que os profissionais pensam no usuário para projetar esse cuidado ou se incluem exatamente esse sujeito/usuário nesta construção de propostas de atenção, nas negociações envolvendo seu atendimento e nas pactuações de rede. Para Agreli, Peduzzi e Silva (2016), a "atenção centrada na pessoa" envolve três elementos-chave: a perspectiva ampliada do cuidado à saúde, a participação da pessoa no cuidado (participação social), e a relação entre profissionais e entre profissionais e usuários. Esses elementos são indicados pelas autoras como imprescindíveis na organização dos serviços e da rede de atenção em saude para um cuidado integral, que se afirma na parceria com usuários, famílias e comunidade.

No caso desse pesquisa, os estudantes descrevem a inclusão da usuária em pensar um “cardápio alimentar" condizente com suas condições socioculturais e a execução de um "projeto Hiperdia” de troca de experiência, de construção de vínculo, de transformação e de produção de um cuidado não imposto pelos profissionais; o que corrobora com a perspectiva de uma "atenção centrada na pessoa", a qual amplia o horizonte de ações, fomenta o trabalho em equipe e constitui um pilar da integralidade (Peduzzi \& Agreli, 2018).

Vale destacar que a integralidade é entendida neste estudo nos três sentidos trazidos por Mattos (2006): ampliação do olhar do profissional de saúde para as necessidades do usuário, que convoca o reconhecimento das condições gerais de vida desses sujeitos; e organização dos serviços e das políticas, articulando assistência e práticas de saúde coletiva, setores e atores para lidar com a complexidade da vida em seu movimento.

Dito isso, corrobora-se com a discussão trazida pelo documento da CHIC (2010), que a "comunicação interprofissional" e a "atenção centrada na pessoa" são duas competências de suporte que influenciam todas as outras, visto que em diferentes contextos elas permanecem, enquanto as outras competências são variáveis. Esta importância foi representada pelo número de vezes que essas duas compareceram nos relatos dos estudantes, sendo as mais mencionadas. Mas também, é possível entender a partir dessa pesquisa, que todas essas competências se relacionam entre si e com os princípios e diretrizes do SUS, de modo que não há um limite tão demarcado entre uma e outra competência.

Seguindo nas discussões sobre as competências presentes nos diários de campo analisados, destaca-se que a "resolução de conflitos" (E2), a "clareza de papéis" (E4) e a "liderança colaborativa" (E4) foram relatadas apenas uma vez. Importante 
problematizar se a restrita menção desses domínios se refere a uma questão de formação, tendo em vista naquele momento, ainda não estarem imersos no debate teórico sobre essas competências, como mencionado acima; ou se esses domínios não fazem parte ainda do cotidiano das práticas.

Historicamente, por exemplo, o conflito foi tomado como algo negativo, aquele que deve ser encoberto e eliminado a qualquer custo, o que pode relacionar-se com o fato dele não ter sido descrito pela maioria dos estudantes deste estudo. Contudo, Cecílio (2005) discute que há no cotidiano dos serviços, uma incontornável diferença entre os modos de olhar dos diferentes atores sociais envolvidos com a ação, que desemboca inevitavelmente em conflitos, os quais denunciam relações de poder e problemáticas do cotidiano que exigem "tomadas de providências" para a transformação necessária a potencialização do SUS. Assim, o autor afirma os sujeitos da saúde como aquele "da ação, como seres práticos, com capacidade para conhecer e (re)criar a realidade humana, inclusive tomando uma postura ativa e criadora diante dos conflitos" (Cecílio, 2005, p.511). Nesse sentido, o estudante que abordou esse domínio em seu diário de campo, afirmou ser possível compartilhar responsabilidades e acordar movimentos de mudanças referentes aos descontentamentos presentes no trabalho, quando expostos esses conflitos.

A "clareza de papéis" para a estudante, refere-se a percepção do seu papel profissional para entender sua função na equipe, não incluindo, aparentemente, o interesse pelo conhecimento das atribuições, dos escopo de práticas e das responsabilidades dos demais membros da equipe (Batista \& Peduzzi, 2018). Pode-se associar tal restrição de entendimento do seu papel à predominância de uma formação ainda isolada, mas por outro lado, na prática comparece, como trazido pelos estudantes, a potencialidade para o cuidado e para formação ao se respeitar e entender os saberes e a contribuição de outras categorias profissionais, possibilitando a associação da saúde mental com a saúde bucal, antes não articulada, por exemplo. A "liderança colaborativa", por sua vez, refere-se, segundo a estudante, a uma participação colaborativa, envolvendo o usuário, que entende-se associada a proposta de cogestão, a qual "aponta para o reconhecimento da possibilidade de instituir compromissos coletivos e para a necessidade de democratizar o poder em todas as dimensões da vida institucional e social" (Guizardi \& Cavalcanti, 2010, p. 1249).

Feitos tais debates sobre as competências, entende-se não ser possível delimitar com exatidão o motivo da "resolução de conflitos", da "clareza de papéis" e da "liderança colaborativa" aparecerem em menor número, contudo, é possível inferir que algumas dificuldades relatadas pelos estudantes podem afetar diretamente a efetivação das competências colaborativas visadas pelo PET-Saúde/EIP, quando, por exemplo, não se entende os objetivos de certas ações como a confecção de cartazes do próprio núcleo de saber, sem troca ou discussão coletiva para a produção desse material.

Dessa forma, é possível apreender a partir desse estudo que as potencialidades da interprofissionalidade se apresentam também como desafios. As trocas de saberes e práticas entre os diversos atores sociais, como dito acima, são trazidas como potencialidades, mas também como grande desafios vivenciados nas relações cotidianas, assim como a comunicação, as discussões coletivas e as relações de poder existentes na AB.

Aponta-se que os modelos disciplinares multi, inter e trans coexistem no campo da saúde coletiva de forma dinâmica. A tradição de modelos educacionais hegemonicamente uniprofissionais e baseados em perspectivas apenas biomédicas é longa e persistente, afetando a compreensão de propostas colaborativas (Peduzzi et al., 2016.). Dessa forma, a superação da compartimentalização das disciplinas e ampliação da perspectiva biomédica são dois desafios marcantes a interprofissionalidade na prática (Lima et al., 2018).

Outra potencialidade vivenciada pelos estudantes inseridos no PET-Saúde/EIP se refere ao desenvolvimento técnico e científico na temática da interprofissionalidade. Tal formação se afirma também como potencialidade diante da dificuldade destacada, da universidade ainda não trabalhar propriamente essa experimentação prática nas graduações da área da saúde. Segundo os participantes, a universidade ainda falha em institucionalizar meios para a efetivação da EIP enquanto aposta 
metodológica; mas, aparentemente, o PET-Saúde/EIP mostrou-se uma experiência potente em direção a este modelo prático. Apesar das dificuldades relatadas, aparentemente, as práticas colaborativas e o desenvolvimento de competências foram bastante oportunizados, envolvendo, conforme indicado pelos estudantes, construção de vínculo também entre categorias diferentes, interesse pelo saber do usuário, melhoria da atenção a partir de uma atuação mais integrada. Em consonância com Capazollo (2017), acredita-se que o processo de aprendizagem dos estudantes ocorre no conjunto de dificuldades e potencialidades, analisando suas práticas e adquirindo novas habilidades.

De todo modo, faz-se importante colocar em relevo alguns desafios destacados pelos estudantes, como a própria dificuldade dos docentes na compreensão da interprofissionalidade, a organização das agendas na direção de garantia de encontros regulares entre as profissões, adesão dos próprios participantes das equipes de referências em relação aos casos que exigem um nível de complexidade maior. A constituição de equipes interprofissionais não pode ser confundida com o simples ato de juntar diferentes profissionais em uma equipe ou espaço (Costa, 2017; Freire Filho; Silva, 2017). O objetivo de estabelecer práticas colaborativas para melhorar o cuidado requer um processo conjunto de aprendizado crítico, reflexivo com situações práticas compartilhadas (Peduzzi, 2017). O trabalho em equipe objetivado pelo PET-Saúde/EIP, conceituado nesta pesquisa, refere-se a construção de grupos interativos, comunicativos, inter e transdisciplinares (Peduzzi et al., 2016).

É nesse cenário que o PET-Saúde/EIP aposta na potência da relação ensino-serviço-comunidade enquanto processo formativo inovador, contextualizado com a realidade das demandas em saúde no território brasileiro (Brasil, 2008). Trata-se de um fator bastante evidenciado pela noção de potencialidade destacada na possibilidade de participação dos estudantes no cotidiano das US, articulando teoria e campo de atuação, visto que o PET possibilitou "vivenciar o que se aprende na faculdade na prática" (E6).

\section{Considerações Finais}

Objetivou-se com esse estudo analisar a vivência interprofissional em saúde a partir das experiências dos estudantes no PET-Saúde/EIP, em seu primeiro ano de funcionamento. Foi possível aprender, ao longo desse primeiro ano do programa, um percurso processual de aprendizagem, inquietações, dificuldades e experiências marcantes de trocas e descobertas na formação dos participantes da pesquisa.

Os resultados permitiram perceber ainda, o quanto as atividades desenvolvidas no PET-Saúde/EIP foram potentes na experiência interprofissional dos participantes da pesquisa. Por meio dessas atividades os estudantes não só conheceram as US e seus territórios de atuação, como planejaram, desenvolveram e participaram de ações, de grupos terapêuticos e/ ou em saúde , do trabalho cotidiano em setores do serviço, dentre outras experiências que até então a graduação não ofertaria ao longo do processo formativo.

Nota-se que nem todas as competências colaborativas foram amplamente relatadas nos diários de campo ao longo do primeiro ano, mas elas compareceram de diversas formas e contextos. Outro ponto marcante foi a escassez de relatos sobre a relação com os tutores e a troca entre professores e estudantes ao longo do primeiro ano. Os relatos trazem mais sobre as relações entre estudantes e profissionais das US (preceptores ou não). Isso pode apontar para a importância de outras pesquisas no sentido de também apreender as concepções e práticas dos docentes na direção da interprofissionalidade, na direção de sempre fomentar a parceria universidade e serviços de saúde.

Por mais que a $\mathrm{AB}$ fomente colaboração e que o SUS compartilhe do entendimento da saúde de maneira ampla, envolvendo cidadania, bem-estar, condições econômicas e sociais, por exemplo, a tradição de formações profissionais uniprofissionais e hierarquizadas permanecem coexistindo na realidade das graduações e dos serviços. Entende-se que a EIP tem 
grande potencial de alimentar as mudanças desses processos formativos engessados, em consonância com os princípios do SUS em cada setor das políticas de saúde.

Por fim, compreende-se que as políticas de saúde e o SUS propiciam um amplo cenário de atuação colaborativa com vistas a uma atenção singular, integral e efetiva. Desse modo, um caminho possível para pesquisas futuras que investiguem a EIP nas graduações das universidades seria, por exemplo, uma análise dos currículos de cada curso com vistas a contribuir para encontrar pontos de interseção entre as graduações e possíveis cenários de aprendizado compartilhados entre estudantes.

\section{Referências}

Agreli, H.F., Peduzzi, M. \& Silva, M.C. (2016) Atenção centrada no paciente na prática interprofissional colaborativa. Interface - Comunicação, Saúde, Educação [online]. 20(59), 905-916. doi: 10.1590/1807-57622015.0511.

Bardin, L. (2009). Análise de conteúdo. Lisboa: Edições 70.

Batista, R.E.A. \& Peduzzi, M (2018). Prática interprofissional colaborativa no serviço de emergência: atribuições privativas e compartilhadas dos fisioterapeutas. Interface - Comunicação, Saúde, Educação [online]. 22(2), 1685-1695. doi: 10.1590/1807-57622017.0755

Belotti, M. (2019). Núcleo ampliado de saúde da família: potencialidades, desafios e impasses para a afirmação de um paradigma emergente em saúde. Tese (Doutorado em Psicologia). Universidade Federal do Espírito Santo.

Brasil (2006). Política Nacional de Promoção da Saúde. Brasília: Ministério da Saúde.

Brasil. (2008). Humaniza SUS: Documento base para gestores e trabalhadores do SUS. 4 ed. $1^{\text {a }}$ reimpressão, Série B, Textos Básicos de Saúde. Secretaria de Atenção à Saúde. Núcleo Técnico da Política Nacional de Humanização. Brasília: Ministério da Saúde.

Brasil. (2011). Política Nacional de Atenção Básica. Brasília: Ministério da Saúde.

Canadian Interprofessional Health Collaborativa (2010). A national interprofissional competence framework. Vancouver: Canadian Interprofessional Health Collaborative.

Capazollo, A.A. (2017). Formação em comum de profissionais da saúde: experiência da Unifesp, Campus Baixada Santista In: Toassi, R.F.C (org.) Interprofissionalidade e formação na saúde: onde estamos? (1 ${ }^{\circ}$ edição, p. 68-80). Porto Alegre: Rede Unida,. p.68-80.

Cecílio, L.C.O. (2005). É possível trabalhar o conflito como matéria-prima da gestão em saúde? Cadernos de Saúde Pública [online]. 21(2), 508-516. doi: 10.1590/S0102-311X2005000200017.

Costa M.V. (2017) A potência da educação interprofissional para o desenvolvimento de competências colaborativas no trabalho em saúde. In: Toassi, R.F.C (org.). Interprofissionalidade e formação na saúde: onde estamos ( $1^{\circ}$ edição, p. 14-27).Porto Alegre: Rede Unida.

Fonsêca, G.S. \& Junqueira, S.R (2017). Políticas de reorientação da formação, qualificação e provimento profissional em saúde: itinerários e interfaces das estratégias indutoras de mudanças. In: Silva Filho, C.C., Garcia Jr, C.A., \& Kovaleski, D.F. VER-SUS Santa Catarina: itinerários (trans)formadores em saúde. Tubarão: Copiart.

Freire Filho. J.R.. \& Silva. C.B.G (2017). Educação e prática interprofissional no SUS: O que se tem e o que está previsto na política nacional de saúde. In: Toassi, R.F.C (org.). Interprofissionalidade e formação na saúde: onde estamos? ( $1^{\circ}$ edição, p-28-39). Porto Alegre: Rede Unida.

Guizardi, F.L. \& Cavalcanti, F. de O.L. (2010). O conceito de cogestão em saúde: reflexões sobre a produção de democracia institucional. Physis: Revista de Saúde Coletiva, 20(4), 1245-1265. doi: 10.1590/S0103-73312010000400010

Hess, R. \& Weigand, G. (2006). A escrita implicada. Revista Reflexões e Debates - Cadernos de educação, 11 (2), $14-25$.

Leite, R.A.F., Brito, E.S., Silva, L.M.C., Palha, P.F. \& Ventura, C.A.A. (2014). Acesso à informação em saúde e cuidado integral: percepção de usuários de um serviço público. Interface - Comunicação, Saúde, Educação [online], 18(51), 661-672. doi: 10.1590/1807-57622013.0653.

Lima, V.V., Ribeiro, E.C.O., Padilha, R.Q. \& Mourthé Júnior, C.A. (2018). Desafios na educação de profissionais de Saúde: uma abordagem interdisciplinar e interprofissional. Interface (Botucatu), 22(Supl. 2), 1549-62. doi: 10.1590/1807-57622017.0722

Lourau, R.(1993). René Lourau na UERJ: Análise Institucional e Práticas de Pesquisa. Rio de Janeiro: UERJ.

Mattos, R (2009). Os sentidos da integralidade: algumas reflexões acerca de valores que merecem ser defendidos. In: Pinheiro, R., \& Mattos, R. (Orgs.) Os Sentidos da Integralidade na Atenção e no Cuidado em Saúde (8ª ed., pp. 43-68). Rio de Janeiro: Cepesc/IMS/Uerj/Abrasco.

Minayo, MCS. (2008). O desafio do conhecimento: pesquisa qualitativa em saúde. São Paulo: Hucitec.

Organização Mundial da Saúde (2010). Marco para ação em educação interprofissional e prática colaborativa. Genebra: WHO.

Peduzzi, M. (2016). O SUS é interprofissional. Interface (Botucatu), 20(56), 199-201. doi:10.1590/1807-57622015.0383

Peduzzi, M., Oliveira, M.A.C, Silva, J.A.M., Agreli, H.L.F. \& Neto, M.V.M (2016). Trabalho em equipe, prática e educação interprofissional. In: Martins, 
Research, Society and Development, v. 11, n. 1, e33811124972, 2022

(CC BY 4.0) | ISSN 2525-3409 | DOI: http://dx.doi.org/10.33448/rsd-v11i1.24972

M.A et al. (org.). Clínica médica: atuação da clínica médica, sinais e sintomas de natureza sistêmica, medicina preventiva, saúde da mulher, envelhecimento e geriatria. Barueri. Editora Manole,. p.171-179.

Peduzzi, M. (2017). Educação interprofissional para o desenvolvimento de competências colaborativas em saúde. In: Toassi, R.F.C (org.)

Interprofissionalidade e formação na saúde: onde estamos? ( $1^{\circ}$ edição, p. 40-48),.Porto Alegre: Rede Unida.

Peduzzi, M. \& Agreli, H.F. (2018). Trabalho em equipe e prática colaborativa na Atenção Primária à Saúde. Interface - Comunicação, Saúde, Educação [online], 22 (2), 1525-1534. doi:10.1590/1807-57622017.0827.

Previato, G.F. \& Baldissera, V.D.A. (2018). A comunicação na perspectiva dialógica da prática interprofissional colaborativa em saúde na Atenção Primária à Saúde. Interface - Comunicação, Saúde, Educação [online], 22(2), 1535-1547. doi: 10.1590/1807-57622017.0647.

Quintanilha, B.C., Sodré, F. \& Dalbello-Araujo, M. (2013). Movimentos de resistência no Sistema Único de Saúde (SUS): a participação rizomática. Interface - Comunicação, Saúde, Educação [online]. 17( 46), 561-573. doi:10.1590/S1414-32832013005000018.

Rolim, L.B., Cruz, R.S.B.L.C. \& Sampaio, K.J.A.J. (2013). Participação popular e o controle social como diretriz do SUS: uma revisão narrativa. Saúde em Debate. 37( 96), 139-147. Disponível em: https://www.scielo.br/j/sdeb/a/dNgCW9WdJJx7VHV7xWkhSHq/?lang=pt\# 